\title{
NADINE GORDIMER EN SU CONTEXTO HISTÓRICO
}

Verónica Volkow*

\section{Nadine Gordimer, extraordinaria} narradora comprometida con la lucha de liberación sudafricana y Premio Nobel de 1991, nació en una familia acomodada, en un pueblo minero en las afueras de Johannesburgo. Su padre fue un joyero, proveniente de Latvia, y su madre tenía ascendencia británica. Los reflejos de estos primeros años fueron captados por su primera novela, The Lying Days (1953), que trata de la vida de Helen, una joven oprimida por la estrechez provinciana. Esta primera obra fue seguida por una incansable producción: Face to Face, libro de cuentos (1949), A World of Strangers, (1958), Occasion for Loving, (1963), que aborda una relación de amasiato adúltero entre un brillante y talentoso pintor negro y una mujer sudafricana blanca. Anne Davis está casada con Boaz Davis, académico estudioso de la música negra y militante pro liberación de los negros a la vez que rival en amores de un hombre oprimido por su raza. Estas contradicciones entre la postura ideológica correcta versus una aplastante vivencia instintiva o emocional son constantes en los personajes de Gordimer y les dan su humana modernidad.

A los volúmenes mencionados los siguen: The Late Bourgeois Life (1966), A Guest of Honour (1970), The Conservationist (1974).

La hija de Burguer aparece en 1979 y es la magistral narración de una vida en diáspora - una joven, llamada Rosa, en honor a Rosa

$$
\text { * Poeta. }
$$


Luxemburgo- hija de padres comunistas sudafricanos blancos, que mueren en prisión al ser detenidos por sus actividades políticas. Rosa vaga de casa en casa, entre algunos amantes y por distintos espacios sociales, aparentemente sin rumbo, pero reconstruyendo dentro de su espíritu su extraordinaria herencia humana. La voz narrativa alterna entre la atalaya omnisciente y la voz interna y apasionada de Rosa, que se desnuda a sí misma a partir de un diálogo imaginario con uno de sus amantes, Conrad; a este disperso estudiante de literatura -para quien el sentido de la vida está limitado a los polos de la sexualidad y la muerte- Rosa Burguer, hija de un comunista sudafricano, intenta revelarle las joyas de su vivencia íntima como hija de militantes; el espectro inusitado de sus experiencias, el profundo hallazgo del amor solidario y destructor de las barreras sociales. En este diálogo interno, imaginario, con el amante pequeñoburgués, se va hilvanando el mosaico magistral que alcanza dimensiones épicas de un vitalísimo retrato mural del momento histórico. Hay en esta gran vista histórico-panorámica, un dejo que nos recuerda los grandes frescos de Diego Rivera, por la vividez existencial, la fidedigna transcripción de los sabores locales, los amores entrañables, el puntuante gozo erótico,

116 la compasión ante las debilidades humanas y un armazón de enorme empuje y lucidez política.

Sólo a aquellos que se comprometen en la acción por el cambio, señalaba Karel Kosik, les es realmente accesible la comprensión de la realidad; sólo mediante la praxis se pueden historiar los hechos desde un punto de vista concreto y verdadero, y no desde el de las falsas apariencias. Quizá por lo mismo los grandes momentos de la novela han correspondido a los puntos álgidos de la historia social que exigen el compromiso del hombre con una transformación radical, el compromiso del hombre con el hombre mismo. Sólo en estos momentos maduran los personajes-tipo de las grandes novelas, como lo plantea Lukács: con su equilibrio entre lo psicológico-interno y el papel social externo, amén del desarrollo de las contradicciones sociales llevadas hacia su máxima exasperación. Son momentos en que el hombre 
puede preguntarse: ¿de qué están hechos realmente los hombres? Ni idealizaciones ni meros títeres de una determinación social.

El revolucionario da su respuesta; y también el gran novelista de una época revolucionaria nos presenta la suya, como la que apuntó Boris Pasternak a principios del siglo XX, o Nadine Gordimer a finales del mismo. Un esbozo que atisbo en La hija de Burguer es que una realidad superior para las relaciones humanas, que es lo que busca todo revolucionario, no está sólo en el futuro sino ya presente en maravilloso germen dentro de la vivencia misma de los militantes. Finalmente es un amor mejor el que los seres valiosos buscan.

En esta novela resulta inolvidable el retrato del matrimonio Burguer, negligentes de su propio bienestar y de su familia a la par que esmerados y heroicos para las obligaciones de un amor que pudiera abrazar a los desamparados en la igualdad. Particularmente poderosa es la presencia de ese paraíso en el aquí y ahora, que es la alberca en casa de Lionel Burger, donde negros y blancos se reúnen los domingos y conviven jovial y fraternalmente. Esta alberca, que abraza amorosamente a los negros, es una verdadera utopía revolucionaria encarnada que no deja de tener su lado oscuro. En esta alberca perece ahogado el hermano de Rosa; los padres comunistas se niegan a tapar el ominoso agujero para que los niños negros siguieran disfrutando de la misma.

Por otro lado, la alberca en casa de Lionel Burguer no puede dejar de recordarnos esa alberca para los negros que existió en Sophiatown. Sophiatown, hasta1955, había sido de las pocas áreas urbanas en la que los negros podían poseer tierras y cuya comunidad multirracial desarrollaba una palpitante e interesantísima cultura; Sophiatown se volvió el hogar de 50 mil negros obreros y presumía de poseer la única alberca para niños negros en todo Johannesburgo. En 1955, con las leyes de relocación del apartheid, una pesada fuerza policíaca entró a Sophiatown allanando casas y forzando a sus residentes a subirse, con sus magras pertenencias rescatadas, a los camiones gubernamentales de reubicación. Las indignadas protestas no fueron escuchadas. Atro- 
pellos como éste se volvieron cotidianos en el régimen del apartheid, que ejerció legalmente su vigencia de 1948 a 1994.

Habría que decir que La hija de Burguer es un libro de contrapuntos: la mutilación familiar debido a la represión política que rodea a Rosa Burguer en contraste con su extraordinaria vitalidad y libertad íntima, su horizonte de mujer joven y hermosa, que son su otra forma de seguridad. También la cruel precariedad y limitación en la movilidad de los negros, sus dolidas ciudades construidas a partir de la basura y despojos que deja la ciudad blanca contrastan con la alegría y la vitalidad, el ritmo, ágilmente espontáneo, de las reuniones políticas entre negros, la regia belleza de sus jóvenes vestidos tan sólo por un par de jeans.

Habría que agregar que, después del levantamiento de Soweto, La hija de Burguer fue un libro prohibido en Sudáfrica y su autora, en tanto que miembro fundador del Congreso de escritores sudafricanos, nunca se permitió el exilio aún durante los momentos más cruentos de la represión del apartheid. No hay duda que Nadine Gordimer pertenece a esa clase de personas que, como diría su gran mártir, Lionel Burguer, "no pueden vivir consigo mismas a expensas de la plenitud 118 de la vida de otros". Quizá como el citado personaje, orgulloso de ser condenado a prisión perpetua porque el cruel juicio le dará la oportunidad de hacer una exposición pública de sus ideas, nuestra autora también consideraría que su vida adquiere la cúspide de su sentido ante la ocasión de ejercer una denuncia.

Al anterior volumen lo siguió July's People, de 1981, novela futurista donde se planteó el derrocamiento del Estado capitalista blanco por una masiva rebeldía de los negros; muchos blancos son asesinados y los aviones y aeropuertos implacablemente bombardeados para que nadie pudiera salir. Maureen y su esposo arquitecto Sames, junto con sus dos hijos, son rescatados por su leal sirviente, July, quien clandestinamente los conduce hasta su propio homeland. En una choza de barro vive la familia de blancos, casi como si estuvieran en un campamento y completamente dependientes del sirviente salvador, mas sin poder renunciar pese a ello a sus prejuicios raciales y de clase, con todo y 
su correcto posicionamiento político. July's People es una noveleta armada con magistral perfección, su trama cerradamente articulada y casi dramática recrea los cánones del rigor aristotélico.

Entre las colecciones de cuentos de Nadine Gordimer se podrían mencionar Six Feet of the Country (1956), Not for Publication (1965), Livingstone's Companions (1971), A Soldier's Embrace (1980). Son cuentos que desarrollan diferentes visos de la problemática de una sociedad dividida racialmente y profundizan en particular en la relación amo sirviente. La violencia de la sociedad postapartheid estaría plenamente representada en The House Gun de 1998. Entre sus últimos libros habría que mencionar Get a Life, de 2005.

Tras de la erradicación legal del apartheid, la incansable militancia de nuestra autora ha otorgado su apoyo a los enfermos del sida en Sudáfrica* y ha tomado la voz como embajadora de las Naciones Unidas para el desarrollo. "El nuevo siglo no será en absoluto nuevo si ofrecemos sólo caridad -señala-el paliativo que tranquiliza la conciencia y mantiene vigente el antiguo sistema de los ricos y los pobres."

En lo personal tendría que decirles que entré a la obra de Nadine Gordimer como quien busca sumergirse en una pedazo de historia viva: para orientarme. Fue tras una visita a Sudáfrica que realicé en 1987 en uno de los momentos más álgidos de la lucha contra el apartheid por parte del Congreso Nacional Africano. Al lado de André Brink y J. M. Coetzee, la obra de Nadine Gordimer, tan magistralmente articulada a la vez que experta en las realidades políticas concretas, era una referencia obligada para comprender la lucha que el pueblo sudafricano estaba librando contra el apartheid en ese momento.

Recuerdo que descendí del avión en Capetown, obedeciendo a la invitación que me había extendido Hein Willemse, académico y escritor en Afrikáans, con el fin de que pudiera escribir un libro

* Claro ejemplo es el volumen editado por Gordimer, Telling Tales (2004), en el cual reúne 21 relatos de escritores de todo el mundo, incluidos cinco premios Nobel de literatura, cuyas ganancias y regalías se han destinado a la educación preventiva contra el VIH/SIDA y al tratamiento de enfermos. En 2007, la editorial Sexto Piso hizo posible su publicación en México. (N. del E.) 
sobre esa extraordinaria epopeya histórica viva. Recuerdo que me ricé el cabello a la afro para intentar pasar por una coloured a pesar de mi cara pálida. Hein era mulato y vivía en uno de los barrios asignados por el apartheid para la gente llamada coloured. Nuestro campo de acción estaba limitado: a las playas se prohibía la entrada de gente que no fuera blanca; las universidades y escuelas también estaban segregadas; los negros y coloureds no podían subir a los vagones de tren asignados para blancos; hacía todavía un año los amores interraciales se pagaban con la cárcel. El apartheid había implementado el sistema de homelands y a los nativos negros se les obligaba a llevar passbooks para poder transitar por los barrios blancos. Los barrios de trabajadores negros en Johannesburgo me llevaron a reminiscencias de favelas latinoamericanas, pero sometidos a una racionalidad y un matemático rigor que los volvía demoníacos. Mi estupor no tuvo límites al enterarme de que parte importante de las protestas contra el apartheid eran libradas por los niños negros en las escuelas.

No existían, en el momento de mi visita, relaciones políticas entre México y Sudáfrica y para obtener permiso de visita tuve que hacer un juramento de que no escribiría nada sobre este país. Juramento que

120 no cumplí, lo que me llevó a vivir todos los días helada por el terror de que la policía pudiera registrar la casa donde vivía y encontrar mis manuscritos. En el momento de salir del aeropuerto, uno de los guardias de seguridad estuvo a punto de revisar mi bolsa de mano, donde imprudentemente llevaba yo mis cuartillas tecleadas más recortes de periódicos: se me congeló el espinazo. Es el mismo miedo con el que vivían todos los que podían presumir de dignidad ética y humana. Corría 1987 y, ya desde 1981, Nadine Gordimer con July's People se había anticipado a la derrota jurídica del sistema del apartheid, que habría de sobrevenir; derrota que tampoco significó la igualdad, por el enorme retraso y pobreza en la que viven las masas negras. No bastaría con dar la lucha en el frente racial -como nos lo plasmaba vívidamente en la alegoría de su libro- ni bastaba con un cambio de gobierno, pues una insoportable y desasosegante precariedad persistiría en la realidad de las mayorías. 